\title{
Giant cavernous hemangioma of the eleventh rib
}

\author{
Heping Huang ${ }^{*}$ (D), Chengdong Ning and Yu Pan
}

\begin{abstract}
Background: Cavernous hemangioma of the rib is extremely rare benign vascular tumor. It is difficult to diagnose in time because both invasive and noninvasive examinations usually fail to distinguish it from other tumors of the rib and other bones.

Case presentation: We described an asymptomatic 44-year-old woman with cavernous hemangioma of the rib that was incidentally discovered in the bathing. The tumor was completely resected by minithoracotomy through posterolateral incision. The pathological tissue was diagnosed as a cavernous hemangioma composed of thinwalled blood vessels and red blood cells.

Conclusions: We reported this case of giant cavernous hemangioma of the rib for its extremely rare occurrence. The preoperative diagnosis is a challenge both clinically and radiologically, and difficult to distinguish this tumor from other tumors of the rib or long bones.
\end{abstract}

Keywords: Cavernous hemangioma, Thoracotomy, Tumor, Diagnosis

\section{Background}

Hemangioma is not a neoplasm, but rather a congenital venous malformation with the potential to develop in all part s of the body. They are predominantly found in the spine and skull and are uncommonly observed in the ribs or long bones $[1,2]$. Cavernous hemangioma of the rib is extremely rare benign vascular tumor, which should be considered in the differential diagnosis of rib tumors, especially in asymptomatic patients.

However, we describe an extremely rare case of a cavernous hemangioma of the rib which was found accidentally in a female patient, the preoperative investigations, and the surgical treatment.

\section{Case presentation}

An asymptomatic 44-year-old female with no medical history or history of trauma to the chest wall was admitted due to a right chest wall mass which was incidentally discovered in the shower. Chest computed tomography (CT) demonstrated a tumor, measuring $8.5 \mathrm{~cm}$ in diameter. Osteosclerosis was present on the top of the lesion

\footnotetext{
* Correspondence: peacehuang@126.com

Department of Cardiothoracic Surgery, The Lu'an affiliated Hospital, Anhui

Medical University, No. 21, west wanxi road, Jin'an district, The Lu'an city
} 237005, Anhui Province, China along with calcification in different places and thickening on the nearby parietal pleura and diaphragm (Fig. 1a,b).

The laboratory investigation including serum tumor marker levels and routine hematologic, blood biochemistry results were normal. The patient underwent right lateral minithoracotomy in which a partial excision of the rib was performed, the intraoperative exploration showed the diaphragm was closely adhered to the giant mass. The large chest wall defect caused by rib resection was reconstructed by performing a polyester patch draft (Fig. 2a,b). When thoracic incision was closed, the right lung was insufflated by anesthetist to expel gas in the right thoracic cavity. No thoracic close drainage was placed to reduce postoperative pain and complications.

The patient had an uneventful recovery and discharged on the sixth postoperative day. Five months after the operation, she was doing well, without any evidence of local recurrence. A definite diagnosis of cavernous hemangioma was made based on histopathology examination results of the resected mass (Fig. 3). The mass was composed of thin-walled blood vessels with dilated channels containing red blood cells and lined by a single layer of endothelial cells (Fig. 4). 


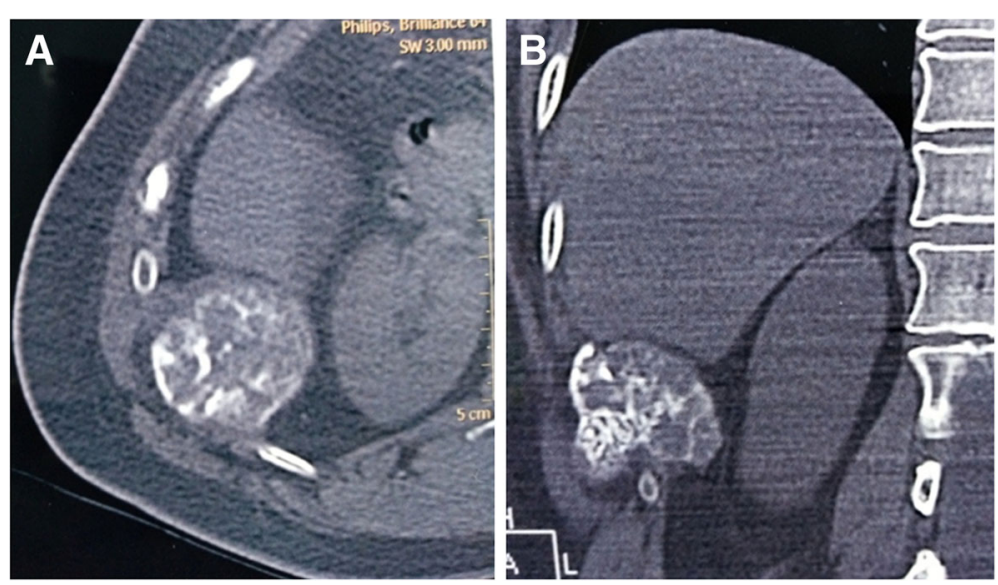

Fig. 1 Chest computed tomography $(C T)$, showing a tumor in the right eleventh rib(a), near the right lower lobe of liver (b), and an osteolytic eccentric expansive mass with sunburst calcification and focal cortical disruption
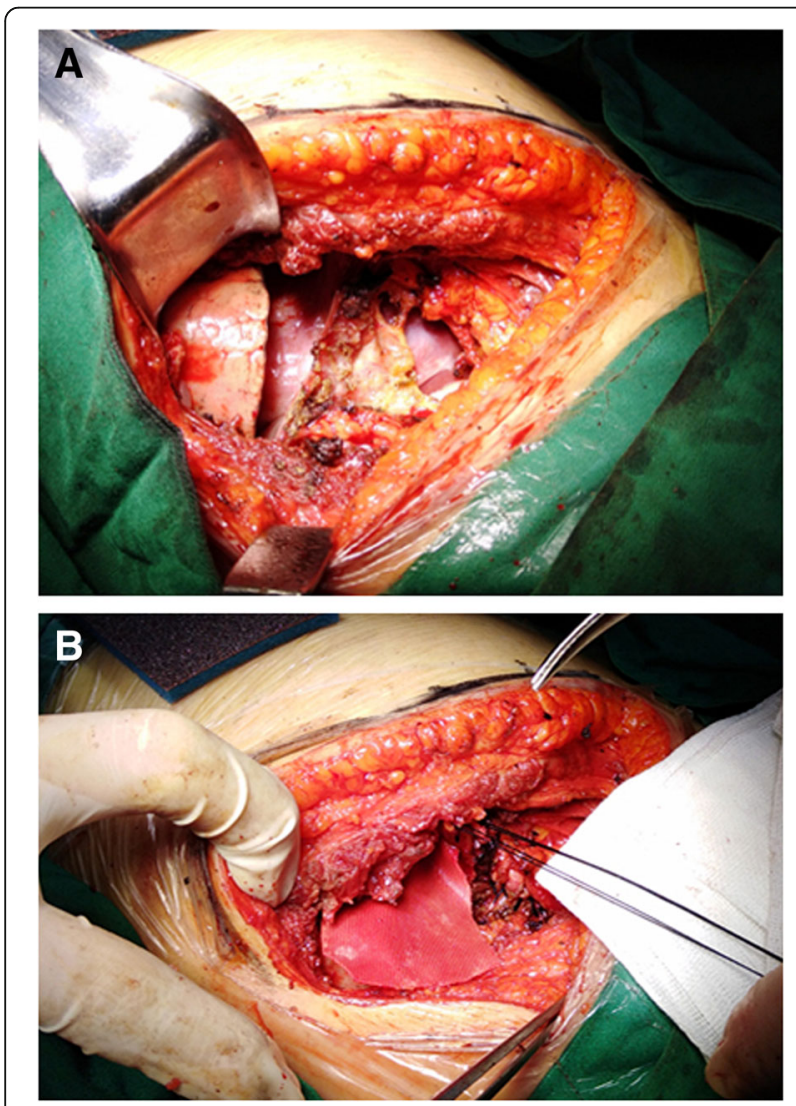

Fig. 2 Intraoperative photographs showed the large chest wall defect (a) caused by rib resection and performance of a polyester patch draft (b)

\section{Discussion}

Most cases of bone hemangiomas develop in the vertebral body or the skull. Hemangioma of the rib is rare, both as a rib tumor and as a bone Hemangioma [3]. It is mostly detected incidentally as it is generally asymptomatic [4], so did our case. However, about $50 \%$ of rib tumors are malignant, and it is difficult to distinguish a rib hemangioma from a malignant tumor such as a chondrosarcoma, metastatic tumor, or multiple myeloma [5].

Hemangioma is a benign neoplasm of blood vessels that can occur throughout the body. Histologically, there are four types of hemangiomas: cavernous, capillary, venous, and mixed type [6]. Cavernous hemangiomas are the most common and account for up to $50 \%$ of all hemangiomas. They consist of dilated vessels lined by a single layer of endothelial cells surrounded by a fibrous stromal layer. Most cavernous hemangiomas involve the medullary and intracortical portion of the bone.

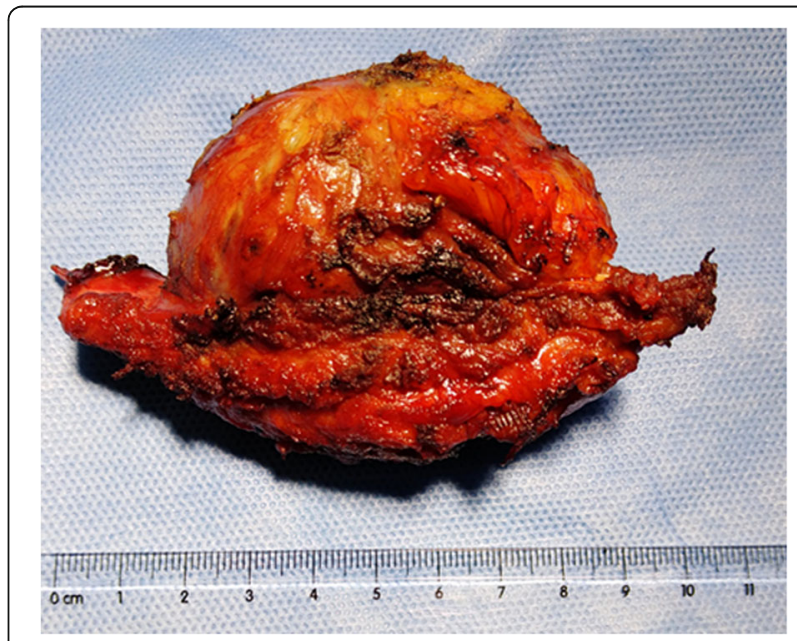

Fig. 3 Macroscopic appearance of resected material 


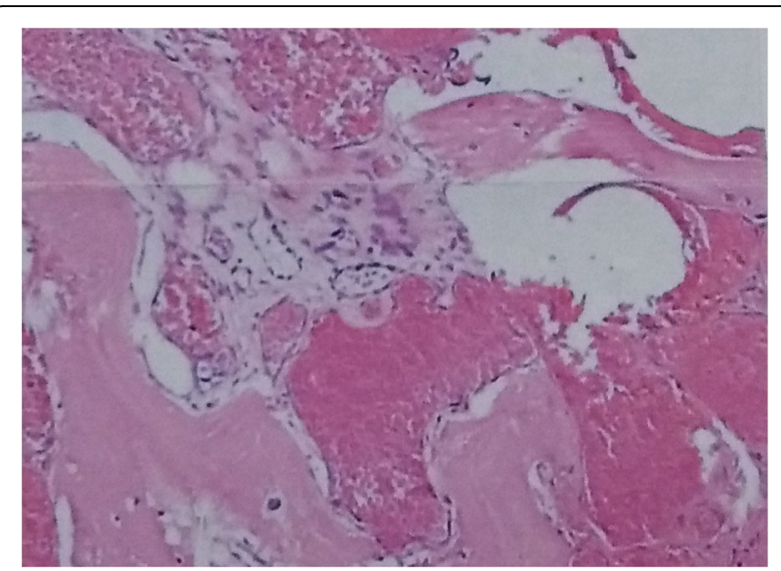

Fig. 4 Histopathologic examination of resected material showing the mass consists of thin-walled blood vessels with single layer of endothelial-cell lining containing red blood cells. (H \& E 100x)

Bone hemangiomas can present with different features on scans obtained by using varying imaging techniques. 18 F-FDG PET can detect the elevated glucose metabolism of cells, which is widely used for differentiation between benign and malignant neoplasms. Malignant lesions tend to be 18 F-FDG avid, however, benign lesions generally show lower 18F-FDG avidity [7]. Choi et al. reported that the mean SUVmax values in the benign rib lesions were $2.5 \pm 1.1$ [8]. Preoperative 18 F-FDG PET examination in our case was not performed because of the patient's poor family economy condition.

Preoperative diagnosis is not always possible due to overlapping radiological features between benign and malignant lesions. It is difficult to make a preoperative definite diagnosis of the chest wall tumors by imagery alone. Therefore, most of the patients with a rib hemangioma undergo rib resection. However, if CT scans show an osteolytic expansive lesion containing sunburst calcifications with low 18F-FDG avidity, a diagnosis of rib hemangioma should be considered [9].

It is the treatment of choice to make a surgical excision of the rib while the histological examination reveals the diagnosis. Excision of rib hemangiomas is a safe procedure with no reported complication after removal or recurrence. Generally, needle biopsy should be avoided because of the risk of life-threatening bleeding or seeding the needle tract unless multiple myeloma or metastatic disease is highly suspected [3].

In addition, temporary embolization using gel foam in rib hemangioma causes shrinkage in size and vascularity of the lesion drastically further easing the excision of the lesion.

We have reviewed 36 cases of rib hemangiomas available in the literature from August 1994 to November 2018 (Table 1). Among these limited cases, the woman was far more than the man in sexual distinction.
Table 1 Characteristics of patients

\begin{tabular}{|c|c|c|c|c|c|c|c|}
\hline \multicolumn{2}{|l|}{ Sex } & \multirow{2}{*}{$\begin{array}{l}\text { Age(years) } \\
\text { Mean and } \\
\text { standard deviation }\end{array}$} & \multicolumn{2}{|c|}{ Location } & \multicolumn{3}{|c|}{ Rib position } \\
\hline Female & Male & & Left & Right & Seventh & Eighth & Others \\
\hline 21 & 15 & $47.0 \pm 16.9$ & 19 & 17 & 12 & 7 & 17 \\
\hline
\end{tabular}

Others: including first,third,forth,fifth,sixth,ninth and tenth rib

Meanwhile, rib hemangioma is more common in middle-aged patients, in which mean and standard deviation values of the age is $47.0 \pm 16$.9. Futhermore, the sickness incidence of the seventh and eighth ribs was significantly higher than the others in lesion region. Nevertheless, there is not much difference between the left and the right side of body in rib lesion position.

\section{Conclusions}

We reported this case of cavernous hemangioma for its extremely rare occurrence in the eleventh rib, which is the false and floating rib and relatively small and delicate. Preoperative diagnosis remains a challenge both clinically and radiologically. It is still difficult to distinguish the disease from other tumors in the rib. Furthermore, surgical resection provides materials for histopathologic diagnosis.

In the future, we hope more cases of rib hemangiomas will be investigated and explored to find out reasons for gender and location differences of rib hemangioma.

\section{Abbreviations \\ $C T$ : computed tomography; H \& E: hematoxylin and eosin}

\section{Acknowledgements}

We greatly appreciate the assistance of the staff of the Department of Cardiothoracic Surgery, the Lu'an affiliated Hospital, Anhui Medical University, and thank them for their efforts.

Funding

None declared.

Availability of data and supporting materials

Not applicable.

\section{Authors' contributions}

$\mathrm{HH}$ was involved in drafting the manuscript. CN designed and revised the manuscript. YP was involved in acquisition of data and preparing the figures. All authors read and approved the final manuscript for submission. Editorial or financial conflict of interest is none.

\section{Ethics approval and consent to participate}

Institutional Review Board Committee of Lu'an affiliated hospital of Science and Technology approved this case report (Ref number: 65-2018). A copy of approval letter is available for review by the Editor of this journal.

\section{Consent for publication}

Written informed consent was obtained from the patient for publication of this case report and any accompanying images. A copy of the written consent is available for review by the Editor-in-Chief of this journal.

\section{Competing interests}

The authors declare that they have no competing interests. 


\section{Publisher's Note}

Springer Nature remains neutral with regard to jurisdictional claims in published maps and institutional affiliations.

Received: 22 December 2018 Accepted: 13 May 2019

Published online: 22 May 2019

\section{References}

1. Ching BC, Wong JSL, Tan MH, Jara-lazaro AR. The many faces of

intraosseous haemangioma: a diagnostic headache. Singap Med J. 2009;50: $195-8$.

2. Nakamura H, Kawasaki N, Taguchi M, Kitamura H. Cavernous hemangioma of the rib diagnosed preoperatively by percutaneous needle biopsy. Gen Thorac Cardiovasc Surgery. 2007;55:134-7.

3. Okumura $\mathrm{T}$, Asamura $\mathrm{H}$, Kondo $\mathrm{H}$, Matsuno $\mathrm{Y}$, Tsuchiya R. Hemangioma of the rib: a case report. Jpn J Clin Oncol. 2000;30(8):354-7.

4. Gourgiotis S, Piyis A, Panagiotopoulos N, Panayotopoulos P, Salemis NS. Cavernous hemangioma of the rib: a rare diagnosis. Case Rep Med. 2010: 254098.

5. Kuo YT, Lin MB, Sheu RS, Liu GC, Chai CY, Chou SH. Imaging diagnosis of cavernous hemangioma of the rib-one case report and review of the literature. Gaoxiong Yi Xue Ke Xue Za Zhi. 1994;10(8):469-73.

6. Kaleem Z, Kyriakos M, Totty WG. Solitary skeletal hemangioma of the extremities. Skelet Radiol. 2000;29:502-13.

7. Choi YY, Kim JY, Yang SO. PET/CT in benign and malignant musculoskeletal tumors and tumor-like conditions. Semin Musculoskelet Radiol. 2014;18(2): 133-48.

8. Choi HS, Yoo le R, Park HL, Choi EK, Kim SH, Lee WH. Role of 18F FDG PET/ $\mathrm{CT}$ in differentiation of a benign lesion and metastasis on the ribs of cancer patients. Clin Imaging. 2014;38(2):109-14.

9. Park JY, Park J g, Lee SJ. Cavernous hemangioma of the rib: a case report. Iran J Radiol. 2016;13(3):e31677

Ready to submit your research? Choose BMC and benefit from:

- fast, convenient online submission

- thorough peer review by experienced researchers in your field

- rapid publication on acceptance

- support for research data, including large and complex data types

- gold Open Access which fosters wider collaboration and increased citations

- maximum visibility for your research: over $100 \mathrm{M}$ website views per year

At $\mathrm{BMC}$, research is always in progress.

Learn more biomedcentral.com/submissions 